\title{
QUESTÕES DE EMPODERAMENTO NO ENSINO DE LITERATURA DRAMÁTICA
}

\section{EMPOWERMENT ISSUES IN DRAMATIC LITERATURE TEACHING}

\author{
Júnio César Batista de Souza ${ }^{1}$ \\ Maria da Glória Magalhães dos Reis ${ }^{2}$
}

DOI: 10.26512/aguaviva.v3i1.12199

Recebido em: 29 mai. 2018

Aceito em: 05 jul. 2018

RESUMO: O objetivo deste artigo é discutir aspectos teóricos sobre empoderamento por meio da prática da Literatura Dramática. Assim, levando em consideração que a escola é o lugar onde os educandos desenvolvem seu conhecimento crítico, estético e científico, acredita-se que a literatura dramática desempenha um papel fundamental na formação do processo de pensamento crítico do discente. O estudo é parte de uma pesquisa de doutorado em fase inicial, que investiga a Literatura Dramática e as Práticas Teatrais no Ensino Aprendizagem de Literaturas. Em uma perspectiva transdisciplinar, propõe uma reflexão com base nas seguintes teorias: Freire (2011) lidando com a autonomia do aluno na construção de seu próprio conhecimento, Zumthor (2007) sobre conceitos de performance e oralidade, Bakhtin (2000) em relação à dialogia em um contexto pedagógico sobre a práxis. Este trabalho está situado no contexto dos estudos que têm interface com a educação e literatura, contribuindo para a expansão do escopo de aplicação das ciências humanas.

Palavras-chave: Literatura; Literatura Dramática; Ensino Aprendizagem; Transdisciplinaridade.

\footnotetext{
${ }^{1}$ Possui graduação em Letras Português-Inglês pela Universidade Estadual de Goiás - UEG (2003), Pós-Graduação em Língua e Literatura pela Universidade Estadual de Goiás - UEG (2007), Bacharel em Artes Cênicas Interpretação Teatral - FADM (2013). Mestre em Linguística Aplicada pela Universidade de Brasília-UnB (2013). Atualmente é Doutorando do Programa de Pós-Graduação em Literatura da Universidade de Brasília (PósLIT/UnB). É professor efetivo de Língua Estrangeira Moderna - Inglês e Língua Portuguesa no Instituto Federal de Educação de Brasília (IFB). E-mail: junioiscariotes@yahoo.com.br

${ }^{2}$ Possui graduação em Pedagogia pela Pontifícia Universidade Católica de São Paulo (1982), mestrado em Letras (Estudos linguísticos, literários e tradutológicos em francês) pela Universidade de São Paulo (2003) e doutorado em Letras (Estudos linguísticos, literários e tradutológicos) pela Universidade de São Paulo (2008). Atualmente é professora do Departamento de Línguas Estrangeiras e Tradução da Universidade de Brasília (LET/UnB). Orienta mestrado e doutorado no Programa de Pós-Graduação em Literatura da Universidade de Brasília (PósLIT/UnB) e possui pós-doutorado em Teatro e Educação na Escola de Comunicação e Arte da Universidade de São Paulo. Email: gloriamagalhaes@gmail.com
} 


\begin{abstract}
The objective of this paper is to discuss theoretical aspects about empowerment in Dramatic Literature Teaching. Thus, taking into consideration that school is where students develop their critical, aesthetic and scientific knowledge, it is believed that the dramatic literature plays a fundamental function in the formation of critical thinking learner process. The study is part of a PhD research in the initial phase which studies the Dramatic Literature and Theater Practices in Teaching and Learning of Literatures. In a transdisciplinary perspective, it proposes a reflection based on the following theories: Freire (2011) dealing with learner autonomy in constructing their own knowledge, Zumthor (2007) on the oral performance of the student, Bakhtin (2000) in relation to dialogy in the pedagogical context about the praxis. This work is situated in the context of studies that have interface with Education and Teaching, contributing to the expansion of the application scope of the humanities.
\end{abstract}

Keywords: Literature; Dramatic Literature; Learning Education; Transdisciplinary.

\title{
INTRODUÇÃO
}

Em pleno século XXI observa-se que muitos contextos de injustiça social que pareciam cenários arcaicos por causa da falta de informação e da existência de barreiras geográficas, ou seja: as distâncias entre escola e educandos, ainda estão presentes em diversas esferas da sociedade brasileira. Portanto, acreditando que somente por meio da educação é que se emancipa intelectualmente o cidadão, pretende-se discutir neste trabalho a questão do “empoderamento" pelo viés da Literatura Dramática. Por conseguinte, as proposições deste texto apontam para um contato com uma literatura que permita ao sujeito experienciar algo que favoreça o pensamento crítico, sensível ao objeto e consequentemente reflita sobre sua forma de enxergar o mundo.

Nessa perspectiva, o exercício com o literário é entendido como um dos elementos capazes de favorecer uma participação social por meio da qual este sujeito tenha maiores possibilidades desenvolver uma formação crítica de forma que lhe sejam garantidos os direitos básicos de todo e qualquer cidadão presentes na Constituição Federal.

$\mathrm{O}$ artigo abre a reflexão explanando brevemente o conceito de "empoderamento" sob o prisma de Schiavo \& Moreira (2005) que transmitem em suas definições o pensamento de Paulo Freire acerca do termo. Assim, abordam-se também aspectos no que tange às implicações do papel do professor no processo de construção do conhecimento por parte do educando.

Em seguida, ressalta-se a importância da Literatura, segundo Eagleton (2003), na perspectiva da construção de discursos, a partir de uma visão da literatura como prática social 
e sobre a leitura dramática como um dos pilares da consolidação desse "empoderamento". Nesse sentido, pretende-se trazer ainda apontamentos sobre Performance na perspectiva de Zumthor (2007) em relação à importância da oralização, da percepção do outro e do corpo na leitura dramática, e algumas reflexões de Stanislavski (2011) sobre a "fala", corroborando as asserções acerca do tema em discussão.

Na última parte, enfocamos as contribuições em relação ao ensino sob o ponto de vista de Bakhtin (2003) por meio de Freitas (2007), fazendo um paralelo entre a teoria Bakhtiniana e o pensamento de Paulo Freire (2011) tentando estabelecer um ponto de contato entre as duas vertentes, de modo a contribuir para as reflexões sobre a literatura dramática e ensino, em específico em relação à questão do “empoderamento".

\section{Empoderamento: A Literatura Dramática como um dos pilares para sua consolidação}

Investigar sobre "empoderamento" requer uma reflexão cautelosa e ancorada em questões culturais, sociais, políticas e educacionais. No contexto desta última, a Educação, e especificamente acerca do pensamento de Paulo Freire, o termo "empoderamento" traz uma conotação que vai além da consciência sobre os fatos, contextos nos quais o ser humano está inserido ou acerca de quais decisões tomar frente a determinadas situações. Preliminarmente, segundo Schiavo \& Moreira (2005), empoderamento

Implica, essencialmente, a obtenção de informações adequadas, um processo de reflexão e tomada de consciência quanto a sua condição atual, uma clara formulação das mudanças desejadas e da condição a ser construída. A estas variáveis, deve somar-se uma mudança de atitude que impulsione a pessoa, grupo ou instituição para a ação prática, metódica e sistemática, no sentido dos objetivos e metas traçadas, abandonando-se a antiga postura meramente reativa e perceptiva (SCHIAVO \& MOREIRA, 2005, p. 59).

Os autores citados trazem para a palavra "empoderamento" o sentido de Paulo Freire, aquele em que o sujeito é um ser ativo e pensante, capaz de identificar-se como alguém que faz parte de um determinado contexto e da necessidade de sua modificação, estabelecendo estratégias com vistas à transformação de sua realidade. Todavia, para se chegar a este patamar de conscientização por parte do indivíduo, diversos fatores se apresentam como requisitos e/ou barreiras para serem ultrapassadas. E um deles é o processo de escolarização formal, o que nos 
leva a refletir sobre o papel do educador.

A sala de aula é um dos locais preferenciais onde se forma o cidadão, pois é neste contexto que ele estabelece suas relações interpessoais capazes de fornecer experiências necessárias para o seu desenvolvimento humano. Logo, a esfera de construção e organização do pensamento crítico, também proporcionada pelo educador, é realizada por meio do estímulo da participação dos alunos nas atividades que sejam permeadas por debates e reflexões, nas quais eles sintam a necessidade e a liberdade de expor seus conceitos e pontos de vista. Este contexto de aprendizagem jamais poderá ser alicerçado na imposição de ideias ou simplesmente na reprodução sistemática de conteúdos acadêmicos, pois de acordo com Freire, "ensinar não é transferir conhecimento, mas criar possibilidades para sua própria produção ou a sua construção" (2002, p. 25). Portanto, podemos aventar que a teoria freiriana se justifica pela necessidade do autoconhecimento do educando, objetivando o rompimento das barreiras que impedem o ser humano de se desenvolver crítica e socialmente.

Mas para que o "empoderamento" ocorra é necessário que o docente esteja consciente do impacto de seu trabalho. Acerca deste tema, Freire (2002) ressalta

O fundamental é que o professor e alunos saibam que a postura deles, do professor e dos alunos, é dialógica, aberta, curiosa, indagadora e não apassivadora, enquanto fala ou enquanto ouve. O que importa é que professor e alunos se assumam epistemologicamente curiosos. Neste sentido, o bom professor é o que consegue, enquanto fala, trazer o aluno até a intimidade do movimento de seu pensamento. Sua aula é assim um desafio, e não uma "cantiga de ninar". Seus alunos não cansam, não dormem. Cansam porque acompanham as idas e vindas de seu pensamento, surpreendem suas pausas, suas dúvidas, suas incertezas (FREIRE, 2002, p. 20).

Nessa reflexão, além da consciência da relação dialógica presente de ambos os lados, educador e educando, percebe-se também a presença do respeito por parte do professor para com o aluno, porque despertar a curiosidade e mantê-la perene é uma atividade trabalhosa, que demanda tempo e até mesmo stress físico e mental. Porém, o profissional da educação imbuído com o propósito de favorecer um ambiente no qual o processo de "empoderamento" seja uma constante, apresenta uma postura incessantemente reflexiva, criativa e motivadora, o que se configura como sinônimo de respeito ao aluno.

Diante dessa breve discussão sobre o "empoderamento" bem como de suas interrelações, reportemos nosso olhar para um dos possíveis pilares de sua consolidação: a literatura dramática. É óbvio que a literatura de forma geral favorece ao leitor construir seus discursos de 
forma crítica, renovando suas percepções, como afirma Eagleton (2003)

Na rotina da fala cotidiana, nossas percepções e reações à realidade se tornam embotadas, apagadas, ou como os formalistas diriam, "automatizadas". A literatura, impondo-nos uma consciência dramática da linguagem, renova essas reações habituais tornando os objetos mais "perceptíveis". Por ter de lutar com a linguagem de forma mais trabalhosa, mais autoconsciente do que o usual, o mundo que essa linguagem encerra é renovado de forma intensa (EAGLETON, 2003, p. 5).

O autor, a partir de sua reflexão sobre o conceito de literatura dos formalistas russos, nos convida a um exercício de reflexão sobre a literatura como uma forma de renovar nossas reações em relação ao mundo e à nossa forma de vê-lo. De fato, a comunicação do homem no dia-a-dia é tão automática que inúmeras vezes passamos pelos acontecimentos e eventos do cotidiano sem termos uma visão crítica deles. Nesse sentido, Eagleton discorre acerca da diferença entre a fala cotidiana e a literatura e declara que a literatura, para os formalistas, "representa uma violência organizada contra a fala comum", ou seja, o texto literário é composto de elementos que eles chamavam de "artifícios" responsáveis por causar o efeito, denominado por eles, de "estranhamento". Esses artifícios seriam os sons, os ritmos, as imagens, as rimas e tudo o que transforma a fala comum, do dia-a-dia, em literatura, em poesia, impondo ao leitor uma "consciência dramática da linguagem" e renovando nossas reações e percepções. Ora, o texto dramático por essência apresenta esses elementos (sons, ritmos, imagens) mencionados, ele é construído com vistas a favorecer essa "consciência dramática", justamente por ser um texto escrito com o objetivo de ser oralizado, colocado na voz e no corpo.

Em nossa perspectiva, a partir de um viés bakhtiniano, os discursos são construídos a partir de enunciados (BAKHTIN, 2003). Apesar de Bakhtin referir-se especialmente ao romance, tomamos alguns de seus conceitos dentro de nossas reflexões sobre o texto dramático. Para o autor, a oração pode ser descrita como uma unidade da língua estanque, neutra, sem expressividade. E, apesar de conter uma informação, ela se encerra nela mesma, pois não está inserida em um contexto, não permite realizar uma ação responsiva.

Em contrapartida, um enunciado é dotado de duas peculiaridades que constroem sentido e o diferenciam da oração. A primeira é a "alternância dos sujeitos do discurso" que permite a atitude responsiva dos falantes, as críticas, as réplicas etc. A segunda é "conclusibilidade", caracterizada por um aspecto interno da alternância dos sujeitos do discurso. Sua percepção é possível porque o falante declara de maneira oral ou escrita algo que expressa a conclusão em 
um contexto específico, dando, como se diz no teatro, a “deixa” para a réplica seguinte.

Por conseguinte, uma oração se torna um enunciado a partir do momento que ela é proferida com "entonação expressiva”, que é caracterizada pela forma como o sujeito a profere. Logo, um enunciado em condições específicas pode representar uma afirmação ou em outro contexto uma ironia, dependendo dos co-enunciadores e da situação de enunciação.

Consequentemente, no trabalho com texto dramático, que necessita da entonação expressiva, condição para sua existência, "a experiência discursiva individual de qualquer pessoa se forma e se desenvolve em uma interação constante e contínua com os enunciados individuais dos outros" (BAKHTIN, 2003, p. 294). Portanto, é no âmbito desta esfera interacional que entendemos a utilização da literatura dramática como um dos pilares para o desenvolvimento do empoderamento do aluno. A leitura tende a favorecer ao sujeito a construção de discursos individuais na medida em que, segundo Todorov, "a literatura pode aproximar os seres humanos uns dos outros, espantar a depressão e ajudar o homem a viver". (2014, p. 76). Vale frisar ainda que a atividade da leitura depende de um processo de apropriação por parte do leitor, levando em consideração que a diversidade de gêneros pode levar a processos diferenciados de leitura: não se lê da mesma maneira um texto de imprensa, uma carta de um amigo, uma mensagem eletrônica ou um texto literário. Dessa forma, cada texto exige atitudes e comportamentos de leitura diferenciados. Isso significa dizer que, por mais que o leitor tenha a sensação de dominar plenamente sua língua materna, não é todo texto escrito em sua língua que poderá lhe proporcionar a fruição, o prazer do texto.

O texto dramático, justamente por sua característica de ser um texto escrito para ser oralizado, exige muito do leitor, no sentido de construir sentidos, imagens e entonações. É dentro dessa perspectiva que apresentamos a proposta do trabalho com os textos dramáticos, acreditando em sua potencialidade para a construção de discursos tanto orais quanto escritos.

Pode-se citar ainda outro fator relevante para o trabalho sobre o texto dramático, tanto em relação a textos da dramaturgia nacional como em relação a peças em línguas estrangeiras. Esse fator seriam as temáticas das obras que podem desencadear discussões sobre os diferentes falares e comportamentos. Em nosso grupo de pesquisa, GEDLLE, foram desenvolvidas várias pesquisas com textos dramáticos em português, inglês, francês e japonês, entre elas minha dissertação de mestrado na qual trabalhei sobre a dramaturgia em língua inglesa (SOUZA, 2013). A diversidade de temas sociais e falares regionais, presentes na literatura dramática, mostra-se relevante na medida em que permite ao educando uma familiarização com elementos culturais de outras regiões de seu país e, no caso das línguas estrangeiras, de países onde se 
falam essas línguas. Por conseguinte, as possibilidades do contato com outras culturas são experimentadas pelo educando, porque ao conhecer um contexto diferente do seu cotidiano, ele se coloca no lugar do outro, experimentando uma sensação, mesmo que ficcional, de tornar-se um pouco o outro. Dessa forma pode-se abrir uma janela experimental, por meio da qual o educando, ocupando um lugar que não lhe pertence, pode experienciar esse lugar favorecendo a experiência da alteridade. Diante desse tema, mais especificamente sobre a literatura, Compagnon (2009) propõe as seguintes contribuições

[...] a literatura desconcerta, incomoda, desorienta, desnorteia mais que os discursos filosóficos, sociológicos ou psicológicos porque faz apelo às emoções e à empatia. Assim, ela percorre regiões da experiência que os outros discursos negligenciam, mas que a ficção reconhece em seus detalhes. [...] A literatura nos liberta de nossas maneiras convencionais de pensar a vida - a nossa e a dos outros -, ela arruína a consciência limpa e má-fé. [...] ela resiste à tolice não violentamente, mas de modo sutil e obstinado. Seu poder emancipador continua intacto, que nos conduzirá por vezes a querer derrubar os ídolos e mudar o mundo, mas quase sempre nos tornará simplesmente mais sensíveis e mais sábios, em uma palavra melhores (COMPAGNON, 2009, p. 47).

Destarte, essa análise singular nos remete ao nosso objeto de pesquisa uma vez que explorar as características do gênero dramático e tratar da literatura semelhante a reflexão de Campagnon, pois ela permeia todas as "regiões" que o autor discute em sua asserção. Vale ressaltar que embora o foco deste artigo seja o suporte literário dramático, as correlações estabelecidas entre os autores que tratam da literatura em geral e os autores específicos do escopo do trabalho objetivam reforçar as proposições acerca do tema empoderamento.

Por meio do texto teatral, o leitor-ator é instigado a vivenciar os comportamentos e emoções das personagens. Dizemos leitor-ator, pois nossa proposta é de que o leitor se transforme em ator, fazendo passar pela voz e pelo corpo o texto trabalhado, que ele seja "intérprete", no sentido postulado por Zumthor, como de "indivíduo que se percebe, na performance, a voz e o gesto, pelo ouvido e pela vista" (2010, p. 239). Dessa maneira, o leitor tem a oportunidade de vivenciar a fruição de suas emoções pela atividade dos seus sentidos e de sua imaginação.

Para finalizar esta seção, apresentamos um quadro I (Figura 1) com alguns aspectos diferenciadores do texto dramático em relação a outros gêneros textuais em função das vantagens constatadas. 


\section{Quadro I - Aspectos diferenciadores do texto dramático}

\section{Figura 1}

\begin{tabular}{|c|c|}
\hline Gênero Textual & Aspectos diferenciadores* \\
\hline \multirow{13}{*}{ Dramático } & Escrito para ser materializado no palco. \\
\hline & Escrito para ser oralizado. \\
\hline & Estrutura com indicações de forma oralização. \\
\hline & Necessita da entonação expressiva. \\
\hline & Impele ao leitor a imaginação de cenas. \\
\hline & Proporciona a interação. \\
\hline & Favorece a construção da linguagem corporal. \\
\hline & Possibilita a construção da linguagem escrita. \\
\hline & Estimula a gosto pela leitura. \\
\hline & Desperta a curiosidade pelo conhecimento. \\
\hline & Permite o contato com outras línguas. \\
\hline & Constrói contextos para o empoderamento. \\
\hline & Apresenta diversidade de temas sociais. \\
\hline
\end{tabular}

\section{A Performance}

Ainda nesta atmosfera na qual a liberdade de experimentação de entonações e de expressão é oferecida aos educandos, com textos em sua língua materna ou na língua estrangeira, o processo de construção de discursos por meio do contato com os textos literários dramáticos vai ocorrendo de forma prazerosa e contínua. Cabe, portanto, colocar em evidência um dos elementos constitutivos desse processo de oralização do texto, a saber: a performance.

Para Zumthor "a performance é o único modo vivo de comunicação poética” (2007, p. 37). Inspirados por essa afirmação, nosso trabalho sobre o texto dramático perpassa as esferas do ritmo, da entonação, das pausas e do volume utilizados pelo enunciador, de modo que, a 
enunciação dramática possa ser, para nosso educando, uma maneira de experimentar essa "comunicação poética".

Stanislavski (2001) igualmente, só que dentro do âmbito da formação do ator profissional, ressalta a importância da "fala", do "dizer o texto" comparando-a com a música

\begin{abstract}
A fala é música. O texto de um papel ou peça é uma melodia, uma ópera ou uma sinfonia. A pronunciação no palco é uma arte tão difícil como cantar, exige treino e técnica raiando pela virtuosidade. Quando um ator de voz bem trabalhada e magnífica técnica vocal diz as palavras de seu papel, sou completamente transportado por suprema arte. Se ele for rítmico, sou involuntariamente envolvido pelo ritmo e tom de sua fala, ela me comove. Se ele próprio penetra fundo na alma das palavras do seu papel, carrega-me com ele aos lugares secretos da composição do dramaturgo, bem como os da própria alma. Quando um ator acrescenta o vívido ornamento do som àquele conteúdo vivo das palavras, faz-me vislumbrar com uma visão interior as imagens que amoldou com sua própria imaginação criadora (STANISLAVSKI, 2001, p. 128).
\end{abstract}

Na citação acima, o teórico russo ressalta a importância dada ao exercício de oralização do texto no sentido de transportar aquele para quem o texto é dirigido, o coenunciadorespectador, para uma emoção, envolvendo-o pelo ritmo e pelo tom.

Podemos dar como exemplo a própria fala cotidiana nos momentos em que percebemos captar a atenção de alguém na situação de enunciação, porém, caso o tema ou a forma como nos comportamos diante de nosso co-enunciador seja contrária às expectativas deste, podemos não ter meios para mantê-lo atento e interessado. Levantamos três elementos que nos parecem essenciais nesse processo e que podem favorecer a expressão e a construção de discursos de nossos educandos, a saber, a percepção do outro, a emoção e o corpo.

Em primeiro lugar, abordamos a percepção dos co-enunciadores acerca da atmosfera na qual se encontram inseridos. Essa percepção apresenta-se como um elemento fundamental para a escolha, por exemplo, das expressões e das estruturas que usamos nos discursos orais, uma vez que essas expressões e estruturas, e a reação que elas causam no co-enunciador, nortearão os rumos que o discurso tomará, dependendo do que é percebido até a decisão de interromper, continuar ou modificar a enunciação. Outro exemplo desse funcionamento da fala, pode ser percebido no discurso político, quando um candidato percebendo que a resposta do público diante de sua performance seja positiva ele segue no mesmo tema, ou ainda faz oscilações para dinamizar sua fala com vistas a emocionar e captar a atenção do público.

Para além da percepção, mas vinculado a ela, um segundo aspecto seria a emoção que é 
mantida ou alterada pela situação de enunciação. Para Zumthor, "A prática poética se situa no prolongamento de um esforço primordial para emancipar a linguagem (então, virtualmente, o sujeito e suas emoções, suas imaginações, comportamentos) desse tempo biológico” (2007, p. 50). A emoção é o que nos tira do aqui e agora e nos faz mergulhar em outro tempo, o tempo da imaginação.

Chegamos ao terceiro elemento, o corpo. Ele é o veículo pelo qual a interação entre os co-enunciadores se materializa por meio do texto dramático. A construção da linguagem perpassa os sentidos do corpo de maneira a se experienciar de forma individual de acordo com a situação de enunciação. Aproveitamos o momento para retomar a ideia da "consciência dramática da linguagem” levantada por Eagleton (2003), como uma possível definição para o conceito de Literatura trazido pelos formalistas, e discutido em seção anterior, com vistas a tentarmos estabelecer uma relação entre a "consciência dramática da linguagem" com o "dramático" do teatro e consequentemente traçarmos algumas considerações acerca do corpo. Partimos, seguindo Zumthor, da premissa de que toda a literatura é teatral, como sublinha o autor, o "termo e a ideia de performance tendem (em todo caso, no uso anglo-saxão) a cobrir toda uma espécie de teatralidade: aí está um sinal. Toda "literatura" não é fundamentalmente teatral?" (2007, p. 21). Ora, para Zumthor não há como separar o corpo do texto que é teatral e que, por consequência, produz modificações neste corpo que o experimenta em suas esferas psíquicas, físicas e comportamentais, pois, na perspectiva de Zumthor, o ato comunicativo seja ele qual for não é apenas uma transmissão de informações, mas é, sobretudo, uma tentativa de modificar o co-enunciador, e é a partir disso ele define a comunicação como um ato de transformação

Ora, quando se toca no essencial (como tende aí o discurso poético... porque o essencial é estancar a hemorragia de energia vital que é o tempo para nós), nenhuma mudança pode deixar de ser concernente ao conjunto da sensorialidade do homem. (ZUMTHOR, 2007, p. 53).

Assim, Eagleton, quando se refere a "consciência dramática" nos parece bastante próximo do conceito de Zumthor acerca das reações do ser humano no que tange ao contato com o texto literário/poético/dramático. Portanto, para Zumthor, o conceito de performance perpassa pela criação literária, pela imaginação do autor/leitor/ator e pelo corpo, incluindo aí a voz, o ritmo 
A leitura "literária" não cessa de trapacear a leitura. Ao ato de ler integra-se um desejo de restabelecer a unidade da performance, essa unidade perdida para nós, de restituir a plenitude - por um exercício pessoal, a postura, o ritmo respiratório, pela imaginação (ZUMTHOR, 2007, p. 66).

Esse exercício pessoal, tanto por parte do educador quanto por parte do educando é o que motiva nosso trabalho unindo os temas de teatro e educação como será discutido na última seção deste artigo.

Ainda no que tange ao tripé percepção do outro/emoção/corpo o qual impulsionam o leitor a desenvolver uma miríade de habilidades e consequentemente um conhecimento acerca de si e do mundo, é fundamental para não perdemos de vista nosso objeto de trabalho, realçar que todas estas questões partem de um único ponto: a literatura. Neste caso a dramática.

Nas palavras de Zilberman (2003), ainda que se referindo a literatura de forma genérica, encontramos uma confluência de sentidos e características com os pontos observados ao longo desta discussão, como verificado no seguinte trecho

[...] a literatura provoca no leitor um efeito duplo: aciona sua fantasia, colocando frente a frente dois imaginários e dois tipos de vivência interior; mas suscita um posicionamento intelectual, uma vez que o mundo representado no texto, mesmo afastado no tempo ou diferenciado enquanto invenção, produz uma modalidade de reconhecimento em quem lê. Nesse sentido, o texto literário introduz um universo que, por mais distanciado da rotina, leva o leitor a refletir sobre seu cotidiano e a incorporar novas experiências (ZILBERMAN, 2003, p. 53).

A autora enfoca com veemência o efeito duplo do contato com a literatura, que a nosso ver, é primordial na atividade com o literário: alimentar a fantasia de maneira que o leitor experiencie a fruição ao passo que utiliza esta experiência para posicionar-se diante das circunstâncias. Este efeito duplo encontra-se presente na realização da performance dos educandos e se modificar e se potencializa todas as vezes que é concretizada.

Com o objetivo de sintetizar as reflexões desenvolvidas nessa seção no que tange aos desdobramentos da performance, demonstramos no quadro II (Figura 2) os elementos essenciais do processo de construção de discurso abordados, com vistas a uma melhor compreensão da temática por parte do nosso leitor. 


\section{Quadro II - Elementos Essenciais do Processo de Construção de Discursos}

Figura 2

Performance

Processo de Oralização Textual
A Percepção do Outro;

\section{Elementos Essenciais}

A Emoção;

O Corpo.

\section{Contextos Pedagógicos de Literatura e Ensino}

Os tópicos tratados até agora nas seções anteriores apresentam interfaces com uma área do conhecimento bastante relevante nos estudos de ensino aprendizagem: a Psicologia. Por isso, faremos uma breve discussão no que diz respeito a uma perspectiva Bakhtiniana da psicologia da educação, desenvolvida por Freitas (2007).

O olhar escolhido para esta reflexão parte da relação entre indivíduo e sociedade que é o ponto de análise do materialismo dialético. Neste viés, a discussão abordada traz Bakhtin como cerne do pensamento, elencando categorias fundamentais para a construção de sua teoria, a saber: o diálogo, a consciência, o texto e o enunciado.

Em sua teoria há uma relação muito próxima com os ideais de Paulo Freire no que tange à Educação. Tal proposição pode ser constatada nas seguintes declarações tanto de Freitas (2007) referindo-se tanto a Bakhtin quanto ao próprio Freire (2011). Freitas (2007) afirma

O eixo que perpassa toda essa interdisciplinaridade é a linguagem. A linguagem passa a ser percebida como fundadora de uma nova reação do homem consigo mesmo e com o mundo. Para Bakhtin (1985), o homem é um ser expressivo e falante e a linguagem é constituidora de sua consciência. $\mathrm{O}$ discurso do sujeito falante é que liberta o homem de sua condição de objeto (FREITAS, 2007, p. 146). 
Em suas reflexões, a autora faz um recorte do pensamento de Bakhtin no tocante à linguagem como um elemento principal responsável pela emancipação do homem como ser pensante e ativo na sociedade. Notoriamente, é pelo discurso que o homem se insere em todo e qualquer contexto social, não necessariamente pela linguagem verbal, mas discurso como forma de construção de sentidos. Em consonância com a premissa, Freire (2011) afirma

\begin{abstract}
A tarefa coerente do educador que pensa certo é, exercendo como ser humano a irrecusável prática de inteligir, desafiar o educando com quem se comunica e a quem comunica, produzir sua compreensão do que vem sendo comunicado. Não há inteligibilidade que não seja comunicação e intercomunicação e que não se funde na dialogicidade. O pensar certo por isso é dialógico e não polêmico (FREIRE, 2011, p. 42).
\end{abstract}

Cabe ressaltar que o pensamento de Freire estabelece também a linguagem e o pensamento dialógico como meios de desenvolvimento intelectual e social do homem. Assim, o ofício do docente revela-se como algo fundamental para proporcionar ao educando possibilidades de exercer a prática do "empoderamento".

De fato, por meio da linguagem, e consequentemente do discurso, observam-se as manifestações de poder, e igualmente da capacidade de reivindicar direitos e lutar pela conquista de espaços públicos. E esta consciência, dos direitos ao espaço de fala, só pode ser adquirida por meio da interação social e da educação uma vez que, segundo Freire, "aprender para nós é construir, reconstruir, constatar para mudar, o que não se faz sem abertura ao risco e à aventura do espírito" (2011, p. 77).

Ainda neste caminho da educação e da construção dos discursos, agora reportando mais uma vez aos conceitos de Bakhtin, nos quais o autor refere-se ao homem em uma investigação ética (BAKHTIN, 2015) do ponto de vista dialógico. É interessante observar que a teoria concentra-se no diálogo com outros "eus" para que a consciência do sujeito seja construída e possa, assim, afirmar-se como tal.

O primeiro eu é a autopercepção, ou seja, é a forma como o próprio sujeito se observa. O segundo é a percepção do sujeito pelos olhos dos outros, o julgamento, as ideias, enfim, o juízo de valor do sujeito externo. E o terceiro é a percepção do outro pelo próprio eu, como eu analiso o outro em sua individualidade. Estes três prismas constituem um processo de tomada de consciência, no sentido de saber quem é este sujeito, qual seu papel em uma relação social com seu tempo e espaço, suas escolhas e suas consequências e a construção de seus discursos, 
permeados pela palavra de outrem, mas libertado dela

É enorme o significado desse processo de luta com a palavra do outro e com sua influência histórica da formação ideológica da consciência individual. Minha palavra e minha voz, nascidas da palavra do outro ou dialogicamente estimuladas por ela, mais cedo ou mais tarde começam a libertar-se do poder dessa palavra alheia (BAKHTIN, 2015, p. 143).

Este tripé da percepção, mencionado anteriormente, nos auxilia na reflexão sobre a concepção do conhecimento ético do homem na construção de seus discursos, na percepção de si e do outro e no seu reconhecimento como indivíduo reflexivo e atuante de forma dialógica e inserido em um contexto social. E na medida em que se aprofunda nas discussões acerca das teorias de Bakhtin, mais convergências com a ideologia de Paulo Freire vão se manifestando. Logo, para finalizar e reforçando nossas asserções, sobre o papel do educador, Freire (2011) argumenta

É por isso, repito, que ensinar não é transferir conteúdo a ninguém, assim como aprender não é memorizar o perfil do conteúdo transferido no discurso vertical do professor. Ensinar e aprender têm que ver com o esforço metodicamente crítico do professor de desvelar a compreensão de algo e com o empenho igualmente crítico do aluno de ir entrando como sujeito em aprendizagem, no processo de desvelamento que o professor ou professora deve deflagrar (FREIRE, 2011, p. 134).

Nesse esforço metodicamente crítico, o texto dramático e as práticas teatrais que possibilitam a passagem do texto pelo corpo e pela voz, parecem, em nossas pesquisas favorecer a que o educando possa entrar em sua aprendizagem como sujeito e consequentemente possa, por meio de uma tomada de consciência de sua condição, formular mudanças e criar condições para que elas possam ser construídas. E ainda, por uma mudança de atitude, ter uma prática, uma ação renovadora, uma práxis, que favoreça seu empoderamento.

\section{CONSIDERAÇÕES FINAIS}

Após discutir questões que julgamos relevantes para uma reflexão sobre a relação entre teatro, literatura e ensino, e tomando como premissa conceitos de Bakhtin de que não há discurso neutro e que todo texto é resultado da confluência de várias outras vozes, espera-se 
que este trabalho possa contribuir para expandir o escopo dos estudos da literatura dramática na medida em que novos pontos de contato possam ser estabelecidos. Também neste artigo, buscamos apresentar uma forma de trabalhar a questão do empoderamento por meio da literatura dramática explorando o máximo de suas potencialidades dentro da esfera de nossos estudos. Assim, acreditamos que ao longo dessa discussão foi possível vislumbrar caminhos que apontam para uma proposta positiva.

Reportando o olhar para a seção "Performance" a qual trata dos três elementos constituintes do processo de oralização textual; a percepção do outro, a emoção e o corpo, verificamos alguns aspectos conclusivos.

O primeiro deles é a expansão lexical por parte dos co-enunciadores acerca da percepção do outro, uma vez que eles utilizarão escolhas distintas de expressões para adequarem-se a contextos linguísticos específicos. Logo, com a diversidade de contextos, automaticamente a variedade de palavras se multiplicará.

O segundo aspecto é a estrutura cíclica no que tange à emoção do leitor. Neste caso, entendemos que ao deparar-se se com este contexto motivacional do suporte literário dramático, o educador tem a oportunidade de potencializar o trabalho tanto da formação intelectual quanto cidadã de seus educandos.

Por fim, o terceiro e último aspecto, ao inserir-se em uma esfera muito específica do trabalho com a literatura dramática, o corpo pode possibilitar o desenvolvimento da expressão do educando na medida que as sensações de autoconfiança e conforto na relação entre coenunciadores são intensificadas com a prática de atividades corporal.

Neste raciocínio, compreendemos que a literatura dramática, como um gênero da literatura, possui um arcabouço significativo no que se refere as possibilidades de desenvolver as habilidades do educando. Logo, é o que se percebe nas palavras de Todorov na seguinte afirmação

O vôo que a educação literária deve proporcionar aos leitores depende da literatura poder desempenhar plenamente sua vocação humanizadora, ao possibilitar ao público a experiência de se tornar um permanente "conhecedor do ser humano". Caso contrário, a literatura estará ao lado de outras mercadorias inúteis, que se impõe no espaço-tempo como mais um entre os muitos obstáculos a serem administrados e os leitores permanecerão às margens da obra e da necessidade de compreendê-la como objeto de fruição vivo, dinâmico e contextualizado, que gera contradições e estabelece a crise. Essa é, ao fim, a concepção de literatura que pode tirar a literatura do limbo e livrá-la do perigo de perder todo o seu potencial revolucionário (TODOROV, 2009, p. 93). 
Aqui, retomando a ideia apresentada na introdução sobre a negligência das escolas acerca da utilização do gênero dramático, entende-se a importância desse tema sob a perspectiva de contribuir tanto para formas alternativas de construção do conhecimento humano quanto para a valorização do gênero literário discutido, tomando como base a asserção de Todorov.

Por outro lado, explorando ainda mais essa vertente do conhecimento, é mister salientar que, no ambiente pedagógico, não basta para o docente propor atividades de leitura com os discentes ou narrar histórias. É imprescindível que ele fomente o interesse pelo suporte literário, realizando discussões em grupos sobre os temas presentes nos textos e inter-relacionando-os com a realidade. Integrando teoria e prática no decorrer das aulas por meio de uma sequência lógica a qual o educando consiga perceber como a linguagem e o meio social estão estruturados. Ademais, fazê-lo perceber como ele pode manipular o texto de forma que isso possa trazer informações que sirvam para o processo de desvelamento e compreensão do mundo. E muito além, uma vez ultrapassado o desvelar, como ele servindo-se dessas informações, consegue modificar o seu contexto e auxilia a outros também transformarem suas realidades.

Em diálogo com autor mencionado a pouco, Larrosa (2003) traz à tona questões significativas quanto a função da literatura em uma esfera de transformação de pensamentos engessados e reprodutivos, como observado neste trecho

A literatura que tem o poder de mudar algo não é aquela que se dirige
diretamente ao leitor, dizendo-lhe como ele tem de ver o mundo e o que deverá
fazer, não é aquela que lhe oferece uma imagem do mundo nem a que lhe dita
como deve interpretar-se a si mesmo e às suas próprias ações; mas, tampouco,
é a que renuncia ao mundo e à vida dos homens e se dobra sobre si mesma. A
função da literatura consiste em violentar e questionar [...] as convenções que
nos dão ao mundo como algo já pensado e já dito, como algo evidente, como
algo que se nos impõe sem reflexão (LARROSA, 2003, p. 126).

É nesse universo de questionamento que também tratamos sobre as possibilidades de se trabalhar com o texto dramático. O romper com paradigmas e resignificar as realidades é o que permeia nossos caminhos.

Em nossas pesquisas no GEDLLE temos experienciado o potencial dessas reflexões e práticas como elementos que favorecem o "empoderamento" do educando considerando-o não unicamente em seus aspectos intelectuais e racionais, mas como um ser humano complexo com seu corpo, sua voz e suas emoções. Acreditamos que o processo de "empoderamento" engloba, 
evidentemente, o discurso crítico e a participação social, mas para isso, não podemos excluir as poéticas do corpo, da voz e da emoção.

E em consonância com nossas asserções, finalizamos com as palavras de Todorov (2010) afirmando que a literatura

\begin{abstract}
nos enriquece infinitamente. Ela nos proporciona sensações insubstituíveis que fazem o mundo real se tornar mais pleno de sentido e mais belo. Longe de ser um simples entretenimento, uma distração reservada às pessoas educadas, ela permite que cada um responda melhor à sua vocação de ser humano (TODOROV, 2010, p. 24).
\end{abstract}

\title{
REFERÊNCIAS
}

BAKHTIN, M. Estética da Criação Verbal. São Paulo: Martins Fontes, 2000.

Teoria do romance I: A estilística. São Paulo: Editora 34, 2015.

COMPAGNON, A. Literatura para quê? Belo Horizonte: Editora UFMG, 2009.

EAGLETON, T. Teoria da Literatura: uma introdução. São Paulo: Martins Fontes, 2003.

FREIRE, P. Pedagogia da autonomia: saberes necessários à prática educativa. São Paulo: Paz e terra, 2002.

FREITAS, M. T. A. Bakhtin e a Psicologia. In: FARACO, C. A. TEZZA, C. Diálogos com Bakhtin. Passo Fundo: Ed. Universidade de Passo Fundo, 2007.

RYNGAERT. J-P. Introdução à análise do teatro. São Paulo: Martins Fontes, 1996.

LARROSA, J. Sobre a lição. In: Pedagogia profana: danças, piruetas e mascaradas. 4. ed. Belo Horizonte: Autêntica, 2003.

SCHIAVO, M. R.; MOREIRA, E. N. Glossário Social. Comunicarte, 2005. Disponível em: <http://www.comunicarte.com.br/glossario_social.pdf> Acesso em: 02 ago. 2015.

SOUZA, J. C. B. O texto dramático: Uma ferramenta para o desenvolvimento da apropriação em LE. Dissertação (Mestrado em Linguística Aplicada). PPGLA/LET/UnB/DF, 2013. Disponível em: <http://pgla.unb.br/?page_id=1333> Acesso em: 21 set. 2016.

STANISLAVSKI, C. A construção da personagem. Tradução de Pontes de Paula Lima. 10 Ed. Rio de Janeiro: Civilização Brasileira, 2001. 
Revista Água Viva

TODOROV, T. A literatura em perigo. Rio de Janeiro: Difel, 2009.

ZILBERMAN, R. A literatura infantil na escola. 11. ed. São Paulo: Global, 2003.

ZUMTHOR, P. Performance, recepção, leitura. São Paulo: Cosac Naify, 2007.

Introdução à poesia oral. Belo Horizonte: Editora UFMG, 2010. 